The Geneva Papers on Risk and Insurance, 17 (June 1980), 82-95

\title{
Deductibles \\ from a Risk Theoretical Point of View
}

\author{
by Hans-Peter Sterk*
}

\section{Introduction}

Deductibles improve the basic model of the insurance business seen as a complete transfer of risk from the policy holder to the insurance company by introducing the variant of partial risk-transfer. In practice they are an important instrument in individual insurance protection. However, the insurance companies regard an increasing demand for non-proportional deductibles with a certain scepticism. They fear that, by doing without that part of the insurance business which lies with the area of minor to average claims, the resulting effect will outweigh the positive aspects and will be, on the whole, dangerous. Consequently, in the case of the partial risk-transfer, great importance is attached to determining the right premium as the price for risk-bearing. Thus ideas concerning deductible rebates are of particular importance in papers dealing with problems relating to this subject.

The same is true of the present article, which proceeds as follows : First, the risktheoretical claim components are outlined and the effect that deductibles have on them is indicated. For this purpose, claim and indemnification models are differentiated. After a general discussion of the dangerousness of risks, the article then explains the dangerousness of deductibles with respect to the special insurance technical aspect of the coefficient of variation. The rebating of deductibles is not least dependent on principles, according to which the risk premiums are determined. Thus in part four, there is a discussion of premium calculation principles in which special importance is attached to a generalised standard deviation principle. Then the last part is concerned with the behaviour of deductible rebates as a function of the underlying claims model and of the premium principles employed in this connection ${ }^{1}$.

* University of Mannheim.

1 Earlier papers dealing with the present theme include the general monograph by Grob [5], which is not particularly confined to insurance technicalities, as well as the articles by Karten [7], Kelly [8], Smith and Head [10], and Strauss [12]. A noteworthy paper by Mack [9], written more recently, will appear shortly.

The present article is based on the main results of the author's thesis [11], which received the Ernst Meyer Prize of the "Geneva Association" in 1979. 


\section{Claim models and indemnification models}

\subsection{Risk-theoretical claim models}

In risk theory, claim number and claim amount are random variables, and they form together an aggregate claim model.

The claim number model consists of a discrete probability distribution :

(1) $\gamma=\left(\mathrm{p}_{0}, \mathrm{p}_{1}, \ldots, \mathrm{p}_{\mathrm{n}}, \ldots\right)$,

where $p_{n}$ means the probability of $n$ claims $(n=0,1,2 \ldots) . p_{0}$ is, therefore, the probability of no-claims.

The expected value $\mu(\gamma)$, and the variance $\sigma^{2}(\gamma)$, give the average claim number, and an indication of the possible deviations from the mean.

The general model of claim amount per claim generally consists of a continuous random variable $\mathrm{X}>0$, whose distribution function $\mathrm{F}(\mathrm{x})$ gives the probability with which the claim amount per claim will not exceed $X$. Expected value and variance of the claim amount are denoted by $\mu(\mathrm{X})$ and $\sigma^{2}(\mathrm{X})$.

$\mathrm{S}>0$ denotes the aggregate claim made up of claim number and claim amount. Its expected value and its variance are, respectively :

$$
\begin{aligned}
& \mu(\mathrm{S})=\mu(\gamma) \cdot \mu(\mathrm{X}) \\
& \sigma^{2}(\mathrm{~S})=\mu(\gamma) \cdot \sigma^{2}(\mathrm{X})+\sigma^{2}(\gamma)[\mu(\mathrm{X})]^{2} .
\end{aligned}
$$

\subsection{Indemnification functionals and indemnification models}

The use of a deductible enlarges the outlined claim models, for, in contrast to complete risk-transfer, there no longer exists any equality between claim and indemnification. In addition to the models for claim number, claim amount and aggregate claim, models for the number of indemnifications, the indemnity amount and the aggregate indemnity have to be constructed. If the form of deductibles is known, the last three components can be derived from the first three components. This is demonstrated below, in the case of straight deductibles.

The contractual determination of a deductible can be described by an indemnification functional which reflects the relationship between claim and indemnity. The arrangement of a proportional deductible of $20 \%$ can be represented, for example, by the indemnification functional :

$$
f(X)=0.8 \cdot X,
$$

while the functional :

$$
f(X)=\left\{\begin{array}{cc}
0 & \text { if } X \leqslant a \\
X-a, & \text { if } X>a
\end{array}\right.
$$

represents the arrangement of a straight deductible of sum a $>0$, in which the deductible is valid per claim. Hybrid forms of these pure proportional and nonproportional deductible forms can be represented in a similar way. 
Since claims which, according to the agreement, do not lead to indemnification payments by the insurance company, are not in every case reported, it is sensible to understand as indemnifications only claims with $f(X)>0$. Thereby, for the rest, an analogy to the arrangement is created, namely the claim amount only amounts to values greater than zero (cf. Bühlmann, [3], p. 4). In the case of proportional deductibles there is, consequently, no difference between claim number and indemnification number, while, in the case of non-proportional deductibles, only those claims which exceed the arranged deductible amount lead to indemnifications. Thus, the number of indemnifications, in comparison to the number of claims, can be drastically reduced, especially in the mass business for small deductibles, since to an overproportional extent, claims tend to concentrate in the realm of small losses.

The exact extent of the reduction can be ascertained with the help of the distribution of the claim amount. A deductible amounting to $a>0$ is exceeded with the probability $\alpha:=1-\mathrm{F}$ (a) per claim, so that the expected number of indemnifications drops from $\mu(\varnothing)$ to $\alpha \cdot \mu(\not)$. In addition, simple reflection shows how probabilities of the claim number distribution are transformed into the indemnification number distribution,

$$
\gamma^{*}=\left(\mathrm{p}_{0}^{*}, \mathrm{p}_{1}^{*}, \ldots, \mathrm{p}_{\mathrm{k}}^{*}, \ldots\right)
$$

where $\mathrm{p}_{\mathbf{k}}^{*}$ means the probabilities of $\mathrm{k}$-number of indemnifications $(\mathrm{k}=0,1,2, \ldots)$.

A k-number of indemnifications can only arise when there first arises a larger, or at least an equal, number $n \geqslant k$ of claims, from which exactly $(n-k)$ number lead to a claim below the deductible amount and k-number lead to a claim above that amount.

The latter occurs exactly with probability

$$
\left(\begin{array}{l}
\mathrm{n} \\
\mathrm{k}
\end{array}\right) \alpha^{\mathrm{k}}(1-\alpha)^{\mathrm{n}-\mathrm{k}},
$$

since $\alpha$ represents the probability of the event that a claim is higher than the deductible amount. Since $n$ claims occur with a probability of $\mathrm{p}_{\mathrm{n}}$, the probability of $k$ indemnifications, consequently, reads as follows:

$$
\begin{aligned}
\mathrm{p}_{\mathrm{k}}^{*}=\sum_{\mathrm{n} \geqslant \mathrm{k}} \mathrm{p}_{\mathrm{n}}\left(\begin{array}{l}
\mathrm{n} \\
\mathrm{k}
\end{array}\right) \alpha^{\mathrm{k}}(1-\alpha)^{\mathrm{n}-\mathrm{k}} & \\
& (\mathrm{k}=0,1,2, \ldots) .
\end{aligned}
$$

The expected value and variance of the distribution of indemnification number are thus written :

$$
\begin{aligned}
& \mu\left(\gamma^{*}\right)=\alpha \cdot \mu(\varnothing) \\
& \sigma^{2}\left(\gamma^{*}\right)=\alpha^{2} \sigma^{2}(\varnothing)+\alpha(1-\alpha) \mu(\varnothing) .
\end{aligned}
$$

Both quantities can be calculated from the corresponding quantity of claim number and the probability of exceeding the deductible amount.

For known claim number models, the transition from claim number to indemnification number distribution proves to be "model maintaining" in the sense that the 


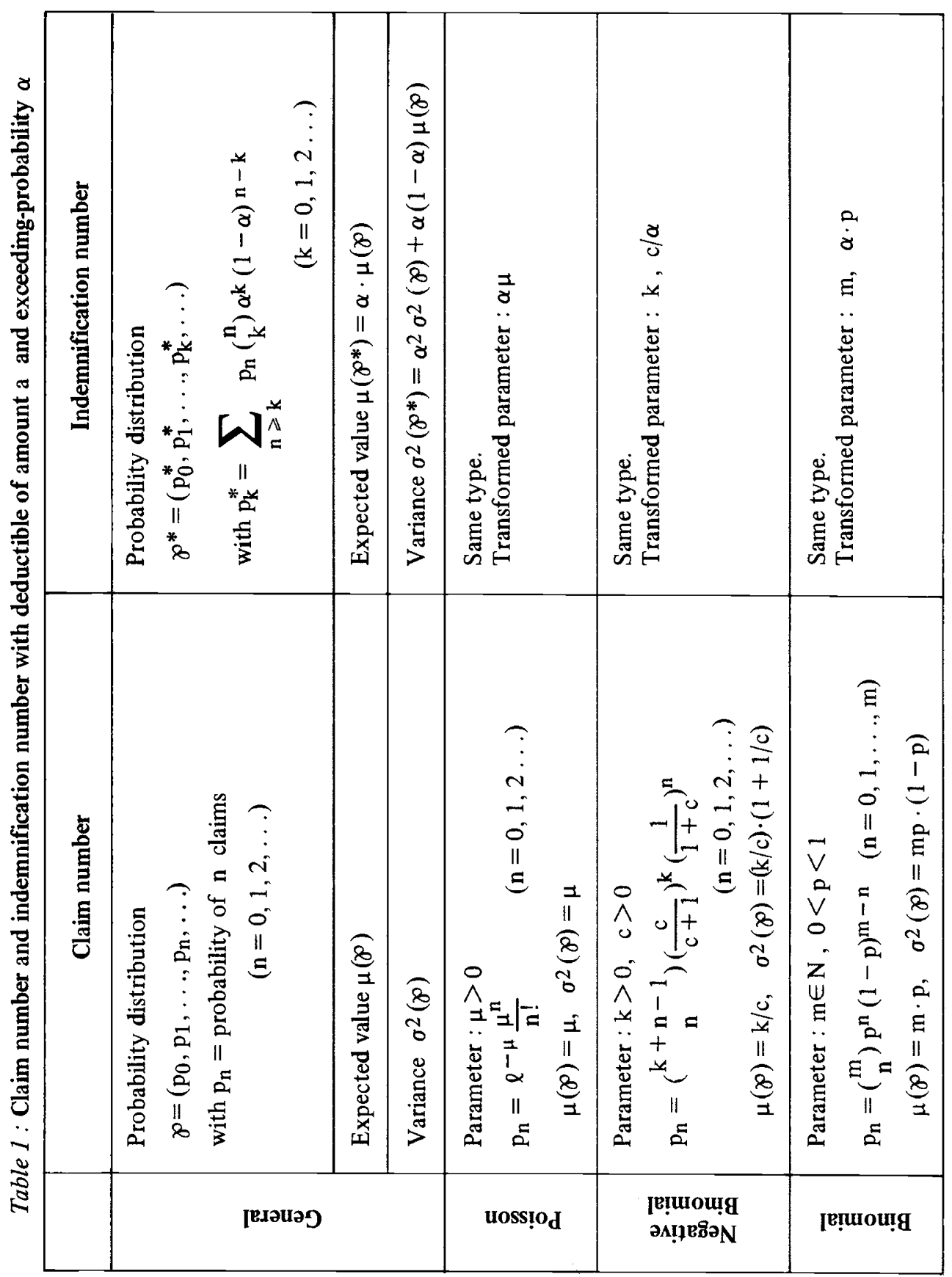


indemnification number distribution belongs to the same model type as the claim number distribution, and is reflected only in a parameter transformation. The parameter transformations in the transition from $\gamma$ to $\gamma^{*}$, being dependent on the probability of exceeding the deductible amount, are specified in table 1 . The corresponding proofs are obtained by direct application of (4), or more elegantly by using the concept of the generating functions (see Feller [4]).

The indemnity amount distribution, $\mathrm{F}_{\mathrm{a}}(\mathrm{x})$, results from a left-sided truncation of the claim amount distribution at point $\mathrm{a}$, and subsequent translation to point zero. This process is illustrated in Figure 1, using a density function. Since the area under the density function up to point a describes the share of claims at the most from amount a, it therefore appears that, depending on how a deductible is used, indemnifications with trifling sums are now relatively much more frequent than was previously the case. ${ }^{2}$

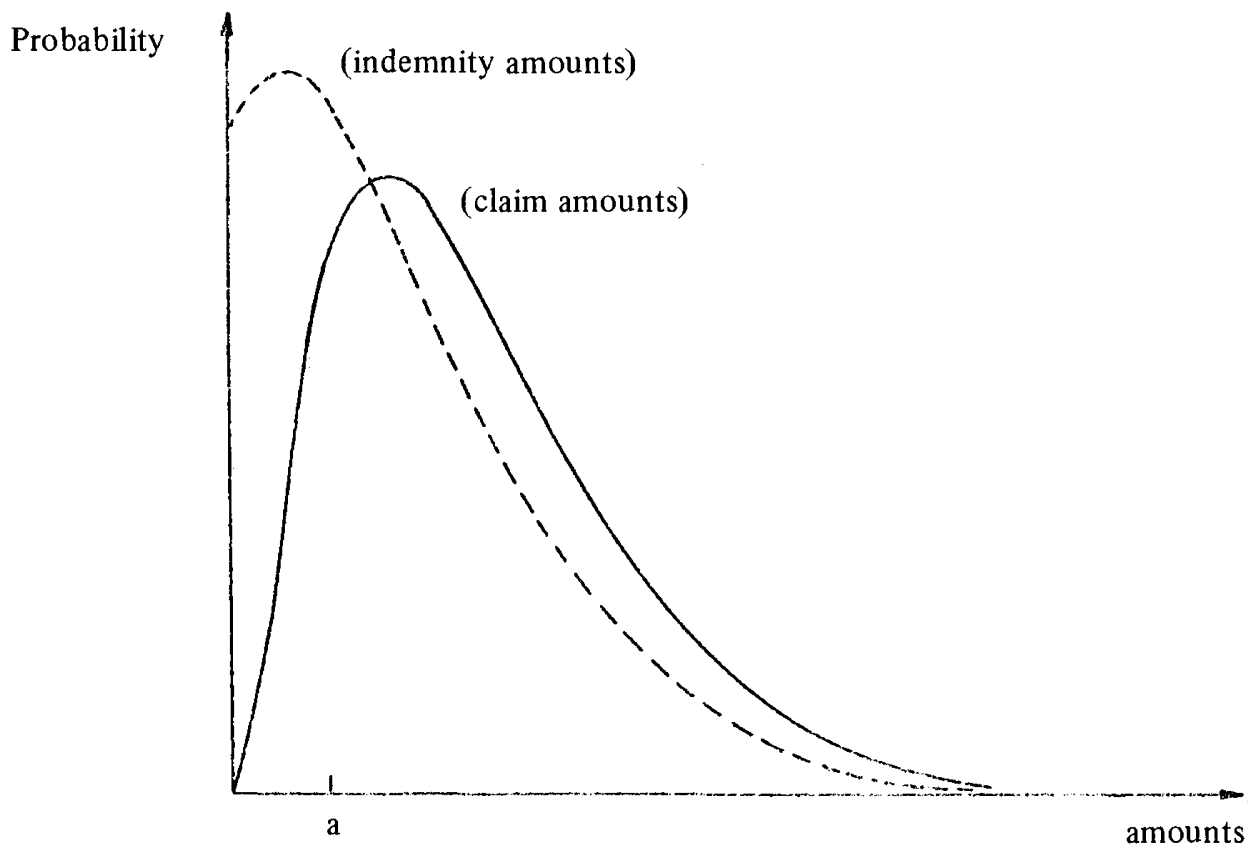

Figure 1: Density functions of claim amounts and indemnity amounts with straight deductible a

Equations (6) and (7) respectively show the formal link between indemnity amount and claim amount distribution, and the expected value of the indemnity amount $X_{a}$

\footnotetext{
${ }^{2}$ Numerical examples are given by Smith and Head ([10], p. 221).
} 


$$
\begin{aligned}
& F_{a}(x)=\frac{F(X+a)-F(a)}{1-F(a)}, x>0 \\
& \mu\left(X_{a}\right)=\frac{\int_{a}^{\infty}(X-a) d F(x)}{1-F(a)} .
\end{aligned}
$$

Depending on the claim amount distribution, the expected indemnification can become smaller or larger than the average claim amount $\mu(\mathrm{X})$. For example, Benktander and Segerdahl [1] characterise a class of distributions for which $\mu\left(\mathrm{X}_{\mathrm{a}}\right)$ increases monotonically as $a$ increases.

Similarly, simple results, as in the transition from claim number to indemnification number distribution, are not to be found in the transformation of known claim amount distributions into the corresponding indemnity amount distributions, for here the transition is not generally "type-maintaining". An exception is the exponential distribution with its noteworthy characteristic that indemnity amount distribution $\mathrm{F}_{\mathrm{a}}(\mathrm{x})$ and claim amount distribution $\mathrm{F}(\mathrm{x})$ always coincide.

The indemnity components derived from the deductible arrangement form, in the usual way, the aggregate indemnity, which is represented by $S_{\mathrm{a}}$. Its expected value and its variance are :

$$
\begin{aligned}
& \mu\left(\mathrm{S}_{\mathrm{a}}\right)=\mu\left(\gamma^{*}\right) \cdot \mu\left(\mathrm{X}_{\mathrm{a}}\right)=\mu(\gamma) \int_{\mathrm{a}}^{\infty}(\mathrm{X}-\mathrm{a}) \mathrm{dF}(\mathrm{x}) . \\
& \sigma^{2}\left(\mathrm{~S}_{\mathrm{a}}\right)=\mu\left(\gamma^{*}\right) \cdot \sigma^{2}\left(\mathrm{X}_{\mathrm{a}}\right)+\sigma^{2}\left(\gamma^{*}\right)\left[\mu\left(\mathrm{X}_{\mathrm{a}}\right)\right]^{2} .
\end{aligned}
$$

\section{The dangerousness of deductibles}

An examination of the extent to which deductibles are to be regarded as dangerous or risk-increasing, calls first of all for a risk-theoretical discussion of the concept of dangerousness. Since deductible arrangements transform risk situations, one must define what is to be understood as the dangerousness of a risk-situation characterised by claim distributions. This task, however, is not clear-cut, and cannot provide a generally applicable solution. The evaluation of risks forms an important part of utility and decision theory, and according to such theories, evaluations without regard to individual preferences and risk-attitudes, expressed by so-called utility functions, are not generally rational. This especially means that simple, parametric, rules determining the dangerousness of claim distributions need not be accepted. Nevertheless, such rules appear to be very important, both in theory and in practice. In contrast to utility theoretical procedures they are easy to apply with relatively less information and, in addition, they have an immediate insurance technical appeal. In particular, they are closely related to the most important parametric premium calculation principles. These rules can, therefore, more easily withstand the pitfall of a lack of rationality.

In the discussion about the dangerousness of risks, much importance should be given to the statistical measures for extent and direction of possible deviations of claim data from its expected value, such as variance and semivariance (see Berliner [2]). In particular, the insurance technical importance of the variance (or its square-root : the 
standard deviation) is underscored by the Chebyshev inequality, which limits the upper probability based on deviations from the expected value.

But in order to compare risks with various expected values taking into consideration their standard deviations, it is more sensible to form the coefficient of variation, which represents a relative measure of deviations, as the relation of standard deviation to expected value :

$$
v(S)=\frac{\sigma(S)}{\mu(S)}
$$

This coefficient can be regarded as a dimensionless risk-measure for a risk with an aggregate claim variable $S$.

By using (2) and by taking into account the coefficients of variation $v(\varnothing)$ and $\mathrm{v}(\mathrm{X})$ of claim number and claim amount, (9) may be rewritten :

$$
v(S)=\sqrt{\frac{[\mathrm{v}(X)]^{2}}{\mu(\gamma)}+[\mathrm{v}(\gamma)]^{2}} \text {. }
$$

A low loss frequency, as well as high relative deviations of the claim number and claim amount, contribute to relatively high fluctuations in the aggregate claim and are, in this sense, to be regarded as dangerous.

This has some importance when one discusses the dangerousness of deductibles. If one inserts the indemnification components $S_{a}, X_{a}$ and $\gamma^{*}$ into (10), then it can be shown that $\mathrm{v}\left(\mathrm{S}_{\mathrm{a}}\right)$, seen as a function of $\mathrm{a}$, increases monotonically-in particular, $\mathrm{v}\left(\mathrm{S}_{\mathrm{a}}\right)>\mathrm{v}(\mathrm{S})$, for every $\mathrm{a}>0$. Thus, although the expected value and standard deviation of the aggregate indemnity decrease with the introduction or increase of the deductible, the relative deviation increases. It can be proved that this is due to the fact that the average indemnification number $\mu\left(\gamma^{*}\right)$ decreases with respect to $\mu(\gamma)$ and, at the same time, the relative deviation $\mathrm{v}\left(\chi^{*}\right)$ increases with respect to $\mathrm{v}(\chi)$, as a glance at relation (5) makes clear. From (10) it becomes clear that these factors result in an increase of $\mathrm{v}\left(\mathrm{S}_{\mathrm{a}}\right)$. In contrast, the coefficient of variation of the indemnity amount distribution does not necessarily increase, but, depending on type and parameter of the claim amount distribution, either remains unchanged, decreases or increases.

The main cause for the dangerous effect connected with deductibles is, consequently, the reduction of the claim number, which, at the same time, is accompanied by an increase in its relative deviation. Consequently, this confirms the view that a high loss frequency is more welcome to assess, from an insurance-technical point of view, than a low loss frequency. For the calculation of deductibles, the increased dangerousness means an adjustment of the safety loading to avoid a higher probability of negative results for the insurance company. This is of direct importance to deductible rebates.

\section{Premium calculation principles}

A premium calculation principle is a functional $\pi$, which assigns a real number $\pi(S)$ to the aggregate claim variable $S$ of a risk. $\pi(S)$ is made up of two components: the net risk premium and the safety loading. 
Before applying a premium calculation principle, a decision must first be made as for which risks are to be combined into a balance-relevant portfolio. A balance-relevant portfolio is a portfolio the goal of which is to obtain a balanced result from premium minus losses by the end of the insurance period.

Every premium calculation principle should also meet certain postulates. The first of them is that the risk premium should at least cover the expected value of losses, i.e. $\pi(S) \geqslant \mu(S)$.

The inequality $\pi(S) \leqslant \operatorname{Max}(S)$ requires that the risk premium may not be higher than the maximum loss. From a practical point of view, this seems obvious, for no one is prepared to pay a premium which exceeds the maximum possible loss. For theoretical reasons, however, it is sensible to admit premium calculation principles which in some cases lead to $\pi(S)>\operatorname{Max}(S)$, and to describe such risks as uninsurable.

Another postulate concerns the combination of independent risks to form a balancerelevant portfolio. It is called the postulate of subadditivity : for $n$ risks $S_{1}, S_{2}, \ldots$, $S_{\mathrm{n}}$ independent from each other, the following inequality should apply :

(11) $\pi\left(S_{1}+S_{2}+\ldots+S_{n}\right) \leqslant \pi\left(S_{1}\right)+\pi\left(S_{2}\right)+\ldots+\pi\left(S_{n}\right)$

where $S_{1}+\ldots+S_{n}$ represents the total result of the portfolio. Put briefly, this postulate requires that insurance should not become more expensive through combining several independent risks. The premium calculation principles which fulfill the equality in (11) are called additive.

A final postulate refers to the concept of dangerousness. It states that, in principle, the more dangerous of two risks should require a higher safety-loading. This severe postulate, which is not always followed when evaluating inhomogeneous portfolios, emphasizes that a connection is necessary between the dangerousness-evaluation of risks and the calculation of the premium.

The simplest and best-known premium calculation principle is the expected value principle, where the net risk premium is equal to the expected value of the risk, and the safety-loading is expressed as a fixed percentage of this expected value :

$$
\pi(S)=(1+\lambda) \mu(S), \lambda>0 .
$$

A weakness of this principle is that it does not take into account the riskiness of the portfolio. It therefore implies some risk-neutrality and, in spite of its simplicity, may be regarded as inferior to the standard deviation principle, where the safety-loading is expressed as a multiple of the standard deviation :

(13) $\pi(S)=\mu(S)+\lambda \sigma(S), \lambda>0$.

This principle is clearly related to the following presentation of the Chebyshev inequality, defining an upper limit for the probability of insurance payments exceeding a given amount :

(14) Prob $[S>\mu(S)+t . \sigma(S)] \leqslant \frac{1}{t^{2}}, t>0$.

For instance, $\lambda=3$ guarantees a probabilistical safety-margin of at least $89 \%$ $\left(=1-1 / 3^{2}\right)$. 
The standard deviation principle is also related to the coefficient of variation, as can be seen from equation (9). The safety-loading, expressed in relation to the net risk premium, consists of the $\lambda$-multiple of this coefficient.

The postulate $\pi(S) \leqslant \operatorname{Max}(S)$ is not necessarily fulfilled by (13). A risk, which leads to a loss of $\$ 10.000$.- with $20 \%$ probability, calls for, by application of (13) with $\lambda=3$, a risk-premium of $\$ 14.000$.-, and would therefore be uninsurable. This contradicts every day experience, and the reason for this contradiction must be sought in the isolated approach, which completely neglects the balancing effect of large portfolios. For example, if (13) is applied to a portfolio of 10.000 such independent risks, this leads to a premium of $\$ 320$.- per head. This reduction of the premium reflects the subadditivity of the standard deviation principle, which is, of course, due to the effect of the law of large numbers.

The idea that a risk should not be calculated without considering the balancing effect of a larger portfolio leads to the following generalisation of the standard deviation principle :

$$
\begin{aligned}
\pi\left(\mathrm{S}_{\mathrm{i}} ; \mathrm{S}_{1}, \ldots, \mathrm{S}_{\mathrm{n}}\right)=\mu\left(\mathrm{S}_{\mathrm{i}}\right)+\frac{1}{\mathrm{n}} \lambda \cdot \sigma\left(\mathrm{S}_{1}+\ldots+\mathrm{S}_{\mathrm{n}}\right) & \\
\lambda & >0, \mathrm{i}=1, \ldots, \mathrm{n} .
\end{aligned}
$$

In this generalized standard deviation principle, it should first be decided in which balance-relevant portfolio the risk will be located. S consequently becomes one of the $S_{i}$. The sum of the premiums calculated from (15) may then be written as :

$$
\begin{aligned}
\sum_{i=1}^{n} \mu\left(S_{1}\right)+\lambda \cdot \sigma\left(S_{1}+\ldots+\right. & \left.S_{n}\right)=\mu\left(S_{1}+\ldots+S_{n}\right) \\
& +\lambda \cdot \sigma\left(S_{1}+\ldots+S_{n}\right)
\end{aligned}
$$

This is, simply, the standard deviation principle applied to the sum $S_{1}+\ldots+S_{n}$, and, therefore, the probabilistical guarantee of a non negative result is ensured.

Strictly speaking, the generalized standard deviation principle represents more than a premium calculation principle as we defined it above, since the premium depends not only on $S_{i}$, but also on $S_{1}, \ldots, S_{n}$. Its peculiarity consists in the fact that the safety loading is calculated collectively and is distributed equally in all portfolio-risks, while the net risk premium deals with the individual aspect of the risk. In contrast to the application of (13) with subsequent calculation by division, all individual premiums will generally be different from each other. They each contain an individual and a collective share.

Utility-oriented premium calculation principles play a theoretically interesting role, although, up to now, they have not been very important in practice. They determine the risk premium in such a way that the utility, after underwriting, remains at least the same as previously. They, thereby, guarantee the maintenance of a certain utility level (see Bühlmann [3], Chapter 4).

However, for calculating utility-preserving premiums, the utility function must first be known and there is no general agreement on the adequate function to be chosen. Doubts about quadratic utility functions in economics and decision theory find insurance 
support in the fact that its use leads to superadditive premiums : insurance per head becomes more expensive with increasing portfolio size (see [11], chapters 3 and 4), which means that the balancing effect of large homogeneous portfolios of independent risks is more than counteracted, in terms of risk premium. In contrast, the family of exponential utility functions leads to additive premiums, and the calculations can be accomplished relatively smoothly when the generating function of the claim number distribution and the moment generating function of the claim amount distribution are known, as is true for some typical cases.

\section{Deductible rebates}

The adequate premium rebate for a deductible depends on whether the remaining premium may be considered as adequate. This concerns first the risk premium. Other premium components, such as operating expenses, profit-loadings or taxes are only indirectly affected by a deductible agreement, and their influence - which is mainly supposed to be of a deterministic nature - should be taken into account only after the rebating of the risk premium.

The question of the adequate risk premium is generally answered by the decision to apply a certain premium calculation principle. If $\pi$ is the premium calculation principle, the premium for the part of risk remaining after agreeing on a deductible $a$ is $\pi\left(\mathrm{S}_{\mathrm{a}}\right)$, and the relative premium reduction may be written :

$$
\frac{\pi(S)-\pi\left(S_{a}\right)}{\pi(S)}
$$

The expected value principle (12), becomes

$$
\frac{\mu(\mathrm{S})-\mu\left(\mathrm{S}_{\mathrm{a}}\right)}{\mu(\mathrm{S})}
$$

after cancellation of $(1+\lambda)$. It can be seen that the relative premium reduction is, in this case, equal to the relative reduction in the expected value of the loss.

Using (2) (5) (7) and (8), the above formula may be rewritten :

$$
\frac{\mu(\varnothing)\left\{\int_{0}^{\infty} X \mathrm{dF}(X)-\int_{a}^{\infty}(X-a) d F(X)\right\}}{\mu(\varnothing) \int_{0}^{\infty} X \mathrm{dF}(X)}
$$

and, after a slight transformation:

$$
r(a)=\frac{\int_{0}^{a} X d F(X)-a[1-F(a)]}{\mu(X)}
$$


The term $\mathrm{r}(\mathrm{a})$ has been called the loss elimination ratio (see Gürtler [6], p. 135). From its easily established concavity, it follows that a straight deductible of $\mathrm{x} \%$ of the sum insured permits a rebate of at least $x \%$ (see Karten [7]), and a similarly rough estimate - relevant only for small deductibles - gives as the highest possible rebate the share of the deductible on average loss, i.e. $r(a) \leqslant a / \mu(X)$. The special behaviour of $r$ (a) depends very much on the type and parameters of the underlying claim amount distribution (see [11], ch. 6 for examples).

The deductible rebates which result from the expected value principle are closely connected to the relative loss elimination, since the calculation of the risk premium is in this case exclusively based on the expected value. This results in not taking into account the danger-increasing effect of deductibles. In order to eschew this problem, the premium calculation must rather be based on the standard deviation principle.

Since the standard deviation principle calculates the safety-loading as a multiple of the standard deviation, it can be supposed that the danger-increasing effect of deductibles will result in deductible rebates which are less than the loss-elimination ratios. This is confirmed by a formal analysis of the rebate formulas, taking as an example a homogeneous portfolio of independent risks.

If all individual risks $S_{1}, \ldots, S_{n}$ of a portfolio of size $n$ are independent, and are represented by the same random variable $S$, the result is :

$$
\sigma\left(\mathrm{S}_{1}+\ldots+\mathrm{S}_{\mathrm{n}}\right)=\sqrt{\mathrm{n}} \cdot \sigma(\mathrm{S}) .
$$

Consequently, the standard deviation principle raises on every portfolio-member the risk premium :

$$
\mu(\mathrm{S})+\frac{\lambda \cdot \sigma(\mathrm{S})}{\sqrt{\mathrm{n}}}
$$

If all portfolio-members choose a deductible of amount $a, \mathrm{~S}$ is replaced by $\mathrm{S}_{\mathrm{a}}$, and the relative reduction of the risk premium may thus be written :

$$
1-\frac{\mu\left(\mathrm{S}_{\mathrm{a}}\right)+\lambda \cdot \sigma\left(\mathrm{S}_{\mathrm{a}}\right) / \sqrt{\mathrm{n}}}{\mu(\mathrm{S})+\lambda \cdot \sigma(\mathrm{S}) / \sqrt{\mathrm{n}}},
$$

which can be rewritten :

$$
\mathrm{q}(\mathrm{a})=1-\frac{\mu\left(\mathrm{S}_{\mathrm{a}}\right)}{\mu(\mathrm{S})} \cdot\left\{1+\lambda \cdot \frac{\mathrm{v}\left(\mathrm{S}_{\mathrm{a}}\right)-\mathrm{v}(\mathrm{S})}{\sqrt{\mathrm{n}}+\lambda \cdot \mathrm{v}(\mathrm{S})}\right\}
$$

$q$ (a) differs from the loss elimination ratio $r(a)$ by the factor in bracket. Since $v\left(S_{a}\right)>v(S)$, this factor is positive, and we may write:

(20) $\quad \mathrm{q}(\mathrm{a}) \leqslant \mathrm{r}(\mathrm{a}) \quad, \quad \mathrm{a} \geqslant 0$.

Like the risk premiums calculated according to the standard deviation principle, the rebates $\mathrm{q}(\mathrm{a})$ are dependent on the portfolio size $n$. With increasing portfolio size they converge from below towards the loss elimination ratios. Thus, the larger the balancerelevant portfolio, the more likely are the deductible rebates to reach their highest values.

Figure 2 provides an illustration based on the relations derived in section 2 . It gives an indication of the rebate range which results from the standard deviation principle. The 
Poisson-distributed claim numbers with average loss-frequency of $10 \%$ and Exponential distributed claim amounts, in addition to $\lambda=3$, have been taken as a basis for calculations. The range is bounded by the extremes of $n=1$ and $n=\infty$. For a straight deductible in the amount of the average loss $(\mathrm{a} / \mu(\mathrm{X})=1)$, the range varies between rebates of $41 \%$ and $63 \%$. The rebates for a portfolio of size $n=900$ have also been plotted.

It has been assumed, until now, that all portfolio members choose a deductible of amount $a$. If this is only true for $\mathrm{n}_{1}$ of them $\left(\mathrm{n}_{1}<\mathrm{n}\right)$, the portfolio should be divided into two homogeneous parts, using the indemnification variables $S_{a}$ and $S$.

The application of the generalized standard deviation principle then leads to the common safety-loading :

$$
\frac{1}{\mathrm{n}} \cdot \lambda \cdot \sqrt{\mathrm{n}_{1} \cdot \sigma^{2}\left(\mathrm{~S}_{\mathrm{a}}\right)+\left(\mathrm{n}-\mathrm{n}_{1}\right) \sigma^{2}(\mathrm{~S})} \cdot
$$

Since $\sigma^{2}\left(\mathrm{~S}_{\mathrm{a}}\right)<\sigma^{2}(\mathrm{~S})$, the safety loading decreases when $\mathrm{n}_{1}$, the number of contracts with deductibles, increases.

The premium for the contracts with deductibles may be written :

$$
\mu\left(S_{a}\right)+\frac{1}{n} \cdot \lambda \cdot \sqrt{n \cdot \sigma^{2}(S)-n_{1}\left[\sigma^{2}(S)-\sigma^{2}\left(S_{a}\right)\right]} .
$$

Comparison of (21) with the premium for full risk transfer - which differs only from (21) by the first term, i.e. $\mu(S)$ in place of $\mu\left(S_{a}\right)$ - shows that the rebates converge to (19) with increasing $n_{1}$. It can also be established that the dependence of rebates on the number of contracts with deductible does not turn out to be as strong as the dependence on the total portfolio size. Therefore, no big errors are likely to appear when the rebates have been calculated according to an incorrectly estimated value of $\mathrm{n}_{1}$.

Most important, the formal analysis of the rebate tariffs, derived from the generalized standard deviation principle, confirms that the rebates must be lower than the losselimination coefficients. In this case too, the loss-elimination coefficients would be justified as rebates only for portfolios of infinite size.

Finally, an examination should be made on how the premium-rebates behave when the premium calculation principle is based on utility theory. It has been shown elsewhere (see [11], chapter 6) that exponential utility functions with exponentially-distributed claim amounts and Poisson-distributed claim numbers lead to deductible rebates which do not differ from the loss-elimination coefficients. However, binomial-distributed claim numbers imply rebates which turn out to be lower, with the difference depending on the degree of risk-aversion. Thus, the danger-increasing effect of deductibles may also have some importance in premium calculation principles based on utility theory.

\section{Conclusion}

A deductible agreement can be represented by a function which transforms the risktheoretical models for claim number, claim amount and aggregate claim into correspond- 


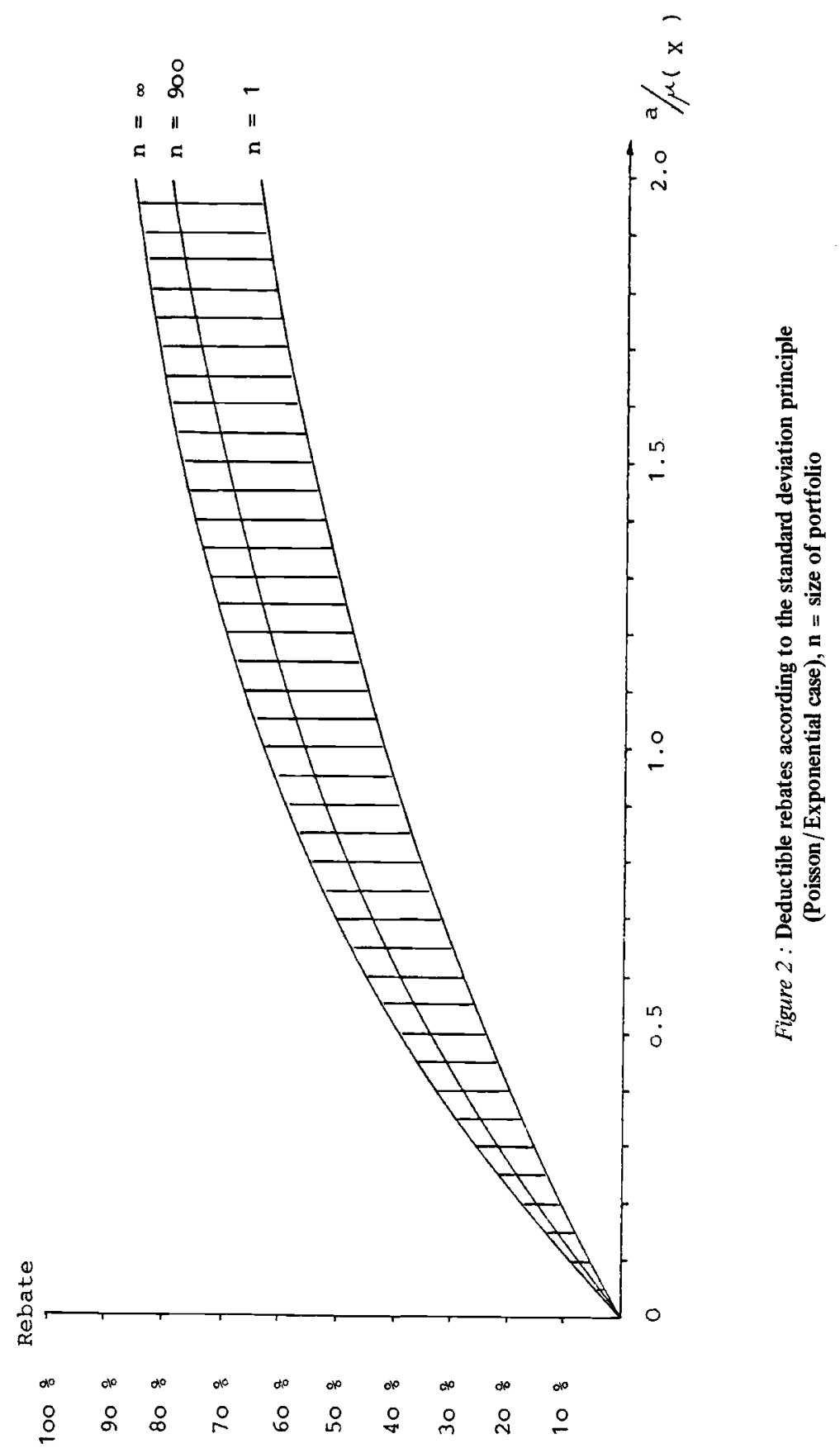


ing indemnification models. It has been shown that, mainly because of the elimination of numerous small claims, the coefficient of variation of the aggregate indemnity distribution increases in the case of a straight deductible. As this danger-increasing element of deductibles is taken into account in premium calculation principles based on a portfolio-linked safety loading, it follows that the resulting deductible rebates turn out to be smaller than the loss elimination ratios, i.e. the percentage decrease of expected losses. This relation between deductible rebates and loss elimination ratios has also been found to be valid when the premium is calculated according to utility theory.

\section{REFERENCES}

1. BENKTANDER, G. and C.O. SEGERDAHL: "On the analytical representation of claim distributions with special reference to excess of loss reinsurance". Transactions of the 16th International Congress of Actuaries, 1960, Vol. 1, 626-648.

2. BERLINER, B.: "A risk measure alternative to the variance", ASTIN Bulletin, 9 (1977), 42-58.

3. BÜHLMANN, H.: Mathematical Methods in Risk Theory, Springer, Heidelberg \& New York, 1970.

4. FELLER, W. : An Introduction to Probability Theory and Its Application, Vol. 1, Wiley, New York, 1968.

5. GROB, K.: Die Selbstbeteiligung des Versicherten im Schadenfall, Wesen und Bedeutung im Rahmen der Privatversicherung, Polygraphischer Verlag, Zürich \& St. Gallen, 1967.

6. GÜRTLER, M. : Die Kalkulation der Versicherungsbetriebe, E.S. Mittler, Berlin, 1936 (2nd ed., Berlin \& Frankfurt/Main, 1958).

7. KARTEN, W.: "Versicherungstechnische Aspekte von Franchisen speziell in der Industrie-Feuerversicherung", Versicherungswirtschaft, 25 (1970), 362-366.

8. KELLY, A.B.: "Deductibles - Theory and Application", Annals of the Society of Chartered Property and Casualty Underwriters, 1966, 77-85.

9. MACK, Th.: "Ueber die Aufteilung des Risikos bei Vereinbarung einer Franchise", (forthcoming).

0. SMITH, M.L., and G. HEAD: "Guidelines for insurers in pricing deductibles", The Journal of Risk and Insurance, 45 (June 1978), 217-238.

1. STERK, H.P.: Selbstbeteiligung unter risikotheoretischen Aspekten, Verlag Versicherungswirtschaft, Karlsruhe, 1979.

2. STRAUSS, J.: "Deductibles in industrial fire insurance", ASTIN Bulletin, 8 (1975), 378-393. 